\title{
P03-3-54 Poster session
}

\section{Vasorelaxant effects of cromakalim on the rat aorta via $\mathrm{Na}-\mathrm{Ca}$ exchange}

Katsuharu Tsuchida ${ }^{1}$, Akiko Takase ${ }^{1}$, Seiichiro Nishida ${ }^{1,2}$, Hiroyasu Satoh ${ }^{3}$

${ }^{I}$ Faculty of Pharmaceutical Sciences, Doshisha Women's College, Japan, ${ }^{2}$ Internal Medicine, Koriyama Seiran Hospital, Japan, ${ }^{3}$ Health Science, Shitennoji University, Japan

\section{[Background]}

Cromakalim exerts vasorelaxation, but its vasodilatory mechanism has not been fully elucidated yet. The objective of the present study was designed to elucidate whether cromakalim dilates the rat aorta by increasing the extrusion of intracellular $\mathrm{Ca}^{2+}$ via $\mathrm{Na}-\mathrm{Ca}$ exchange or not. The degree of the contribution of $\mathrm{Na}-\mathrm{Ca}$ exchange to vasodilatation is still controversial in the rat aorta.

[Methods]

The rat aorta, excised under anesthesia, was cut into helical strips and its endothelium was removed. The contractile force of the strips was measured in the Krebs-Henseleit solution.

[Results]

A K ${ }^{+}$channel opener, cromakalim $\left(10^{-7} \sim 3 \times 10^{-5} \mathrm{M}\right)$ relaxed the A23187 $\left(10^{-5} \mathrm{M}\right)$-induced contraction in the presence of nicardipine $\left(3 \times 10^{-6} \mathrm{M}\right)$ in the rat aorta. However, the relaxant effect of cromakalim $\left(10^{-7} \sim 3 \times 10^{-5} \mathrm{M}\right)$ on the A23187 $\left(10^{-5}\right.$ $\mathrm{M})$-induced contraction was attenuated in the presence of glibenclamide $\left(10^{-5} \mathrm{M}\right)$. Cromakalim $\left(10^{-7} \sim 3 \times 10^{-5} \mathrm{M}\right)$ also relaxed the $\mathrm{Na}^{+}$-free-induced contraction in the absence of nicardipine, but the relaxant effect of cromakalim on the $\mathrm{Na}^{+}-$ free-induced contraction was also attenuated in the presence of glibenclamide $\left(10^{-5} \mathrm{M}\right)$. The treatment with benzamil $\left(3 \times 10^{-5} \mathrm{M}\right)$ or KB-R7943 $\left(10^{-5} \mathrm{M}\right)$ suppressed the vasorelaxant effects of cromakalim $\left(10^{-7} \sim 3 \times 10^{-5} \mathrm{M}\right)$ on the A23187 $\left(10^{-5}\right.$ $\mathrm{M})$-induced contraction in the presence of nicardipine $\left(3 \times 10^{-6} \mathrm{M}\right)$. Caffeine $(25 \mathrm{mM})$-induced contraction was estimated in the presence or absence of cromakalim $\left(10^{-5} \mathrm{M}\right)$ in the $\mathrm{Ca}^{2+}$ and/or $\mathrm{Na}^{+}$-free solution. Cromakalim suppressed the caffeine-induced contraction in $\mathrm{Ca}^{2+}$-free Krebs-Henseleit solution but not suppressed the caffeine-induced contraction in $\mathrm{Ca}^{2+}$ and $\mathrm{Na}^{+}$-free solution. The vasorelaxant effect of cromakalim was attenuated under the conditions without $\mathrm{Na}^{+}-\mathrm{Ca}^{2+}$ exchange function.

[Conclusions]

These results suggest that cromakalim exerted the vasorelaxant effects by promoting the forward mode $\mathrm{Na}^{+}-\mathrm{Ca}^{2+}$ exchange due to the membrane hyperpolarization to some extent, and this mechanism may especially be pivotal to reduce the increase in the cytosolic $\mathrm{Ca}^{2+}$ concentration in the rat aorta. 